\title{
ON-ORBIT DEMONSTRATION OF A SUN SENSOR ON THE MICRO-SATELLITE MAIDO-1
}

\author{
HIROSHI OKUBO \\ Department of Aerospace Engineering, Osaka Prefecture University, \\ Sakai, 5998531, Japan. \\ okubo@aero.osakafu-u.ac.jp
}

\begin{abstract}
A 50-kg-class microsatellite "MAIDO-1 (SOHLA-1)" was launched, along with six other piggyback subsatellites, by a Japanese H-2A rocket on January 23, 2009. The fundamental and detailed designs of the satellite were developed by university students under the technical guidance of the Japan Aerospace Exploration Agency (JAXA). A stringtype sun sensor (Fudai Sun Sensor; FSS) was also developed by the students with the technical assistance of JAXA and Advanced Engineering Services (AES) Co. Ltd. The FSS was mounted on the satellite as an experimental component. This paper reports the development of MAIDO-1 and FSS as well as the satellite operation by the students and the results of on-orbit experiments.
\end{abstract}

ABSTRAK: Satu mikrosatelit kelas $50 \mathrm{~kg}$ "MAIDO-1 (SOHLA-1)" telah dilancarkan, bersama enam lagi subsatelit gendong, dengan menggunakan roket $H-2 A$ (Jepun) pada 23 Januari, 2009. Rekabentuk satelit yang asas dan terperinci dibangunkan oleh para pelajar universiti di bawah bimbingan teknikal Agensi Explorasi Aeroangkasa Jepun (Japan Aerospace Exploration Agency (JAXA)). Sejenis penderia matahari bertali (Fudai Sun Sensor; FSS) juga dibangunkan oleh para penuntut dengan bantuan teknikal dari pihak JAXA dan Advanced Engineering Services (AES) Sdn. Bhd. FSS telah dilekapkan ke satelit sebagai komponen eksperimental. Kertas ini membentangkan perkembangan MAIDO-1 dan FSS, operasi satelit oleh pelajar-pelajar dan keputusan eksperimen semasa dalam orbit.

KEYWORDS:microsatellite; sun sensor; satellite operation;on-orbit experiment; attitude control component

\section{INTRODUCTION}

A $50 \mathrm{~kg}$ class micro-satellite "MAIDO-1 (SOHLA-1)" has been developed by Space Oriented Higashiosaka Leading Association (SOHLA), a corporation of middle-sized enterprises in Higashi-Osaka and Kansai district [1]-[3].The configuration and specifications of MAIDO-1 are shown in Fig. 1 and Table 1. The fundamental design and detailed designs of the bus-systems has been carried out by the students of Osaka Prefecture University under the technological support of Japan Aerospace Exploration Agency (JAXA). The main objectives of the "SOHLA-1" program is to realize the low-cost and short term development of a micro-satellite on the basis of a technology transfer between "MicroLabSat" and the micro-satellite design technique of JAXA with the cooperation of a small and medium enterprise group in Higashi-Osaka and Osaka Prefecture University. One of the main objectives is to provide the engineers and students training opportunities for developing the 
micro-satellite and learning systems design technique. The "Small Satellite Design Workshop" was conducted by Osaka Prefecture University, JAXA, and SOHLA in order to study the design problems of MAIDO-1. The design and development of the MAIDO-1 bus system were carried out by graduate and undergraduate students of Osaka Prefecture University and Ryukoku University under the technical support of JAXA. The vibration test, thermal balance test, etc., were carried out at Tsukuba Space Center and Creation Core Higashi-Osaka, where the students participated in the planning, execution, and post-analysis of the tests and obtained valuable experience.

The main missions of MAIDO-1 were the engineering demonstration of newly developed on-board instruments such as a monitor camera, GPS receiver, and broadband VHF digital interferometer for lightning observation from space. Among them, aprototype sun sensor, named Fudai sun sensor (FSS) was developed by the students of OPU with technical support from the JAXA and Advanced Engineering Services (AES) Co. Ltd., and it was loaded onto MAIDO-1. The FSS works on the "one string method," whereby a string is used to create shade on a linear sensor [4]. The string method has two advantages over the precision slit system, e.g. [5]. First, it is easier to manufacture and has less constraints of the measurement range. Second, it is possible for even smaller downsizing for small and micro satellites. Moreover, it can also put in perspective for microminiaturization through Micro Electro Mechanical Systems (MEMS) technology. The aim of developing this sensor was to demonstrate a new type of sun sensor based on the string method and to apply the technique for developing satellite components at the university. For this purpose, the breadboard model (BBM), engineering model type 1 (EM1), engineering model type 2 (EM2), and flight model (FM) of the FSS were developed.

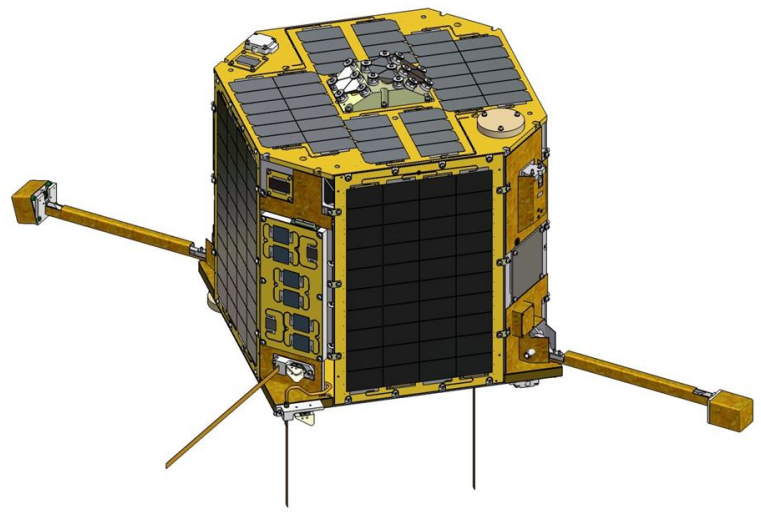

Fig. 1:Configuration of MAIDO-1.

The "MAIDO-1"was successfully launched, together with other six piggy-back subsatellites, by a Japanese H-2A rocket on January 23, 2009. The mission experiments conducted in the regular operation period (about three months) were all successful, which include the on-orbit demonstration of monitor cameras, FSS, boom deployment, and lightning observation from space. The operation was continued for about 9 months, and the satellite system was shut down on the 10th of October by a command from the ground.This paper reports the developmentof MAIDO-1 and FSSand on-orbit experiment of FSS which Osaka Prefecture University was mainly participated. 
Table 1: Specifications of MAIDO-1.

\begin{tabular}{|l|l|}
\hline Size & $50(\mathrm{~W}) \times 50(\mathrm{D}) \times 50(\mathrm{H}) \mathrm{cm}$ \\
\hline Mass & $50 \mathrm{~kg}$ \\
\hline Orbit & LEO, Sun synchronous \\
\hline Communication & S-band; Amateur band \\
\hline Altitude control & Spin stabilized, $3 \mathrm{rpm}(\mathrm{TBD})$ \\
\hline Power control & PPT control \\
\hline $\begin{array}{l}\text { Thermal } \\
\text { control }\end{array}$ & Passive control \\
\hline $\begin{array}{l}\text { Operation } \\
\text { period }\end{array}$ & $>3$ months \\
\hline
\end{tabular}

\section{DEVELOPMENT OF MAIDO-1}

The design and development of the MAIDO-1 bus system were carried out by graduate students and the students of Osaka Prefecture University and Ryukoku University. They undertook the development of a subsystem in which each special research field was intensive; moreover, they studied satellite design technology under researchers and specialists from JAXA; furthermore, they also studied manufacturing technology from the engineers of Higashiosaka.

The "Small Satellite Design Workshop" was jointly conducted by Osaka Prefecture University, JAXA, and SOHLA in order to study the design problems of SOHLA-1. The workshop was held more than 30 times during FY 2004-2005. The vibration test, thermal balance test, etc., were performed at the Tsukuba Space Center and Creation Core Higashi Osaka, where the students participated in the planning, execution, and post-analysis of the tests and obtained valuable experience. Outline of the systems design on the electrical power system, structural system, thermal control system, and attitude control system, in which Osaka Prefecture University was mainly involved, is presented as follows:

In microsatellites, the Electric Power System (EPS) design is a very important factor because the surface area available is limited. Several methods of EPS analysis were employed in order to confirm the feasibility of the satellite system. An EPS simulator has been developed to examine the electrical power control parameters and a new peak power tracking (PPT) algorithm has been proposed.

From the vibration tests performed on the structure thermal model, it was found that the damping characteristic of the initial design is very low. Several vibration suppression systems have been experimentally examined. Among these, the vibration suppression system using polyimide tape was found to be very effective, and the magnitude of vibration response of the revised satellite structure was reduced to $1 / 3$ rd of the original.

In order to verify the validity of the preparatory design and analysis, the thermal balance test has been performed two times. The experiments have been conducted using a skin heater 
and an IR cage. A new design method has been developed for the thermal control system of a small satellite using a genetic algorithm. The proposed method is effective in reducing the computational time and is suitable for the thermal control system design of a small satellite.

The primary method of attitude control is the spin stabilized control. Nutation damping and spin control are achieved by driving magnetic torques based on onboard computing. Spin axis estimation is achieved by using solar and magnetic sensors; spin axis control is based on offline computing. A novel improved spin axis control algorithm has been developed for MAIDO-1, and its effectiveness has been examined both by a simulation test and a flight test using MicroLabSat.

\section{DEVELOPMENT OF SUN SENSOR}

A sun sensor named "Fudai Sun Sensor (FSS)" was developed by Osaka Prefecture University with the technical support of the JAXA and AES. The FSS works on the "one string method," where a string is used to create shade over a linear sensor in order to geometrically measure the angle between the sun direction and the spin axis (total sun angle). The string method has two advantages over a precision slit system. First, it is easier to manufacture and has less constraints on the measurement range. Second, it is possible to further downsize it for application to small and microsatellites. Moreover, it can also put in perspective for microminiaturization through the micro-electromechanical system (MEMS) technology. The aim of developing this sensor was to present a novel sun sensor based on the string method and to apply the same technique for developing satellite components at the university. As shown in Fig. 2, the breadboard model (BBM), engineering model type 1 (EM1), engineering model type 2 (EM2), and flight model (FM) of the FSS were developed. The FM of the FSS was completed in August 2007.

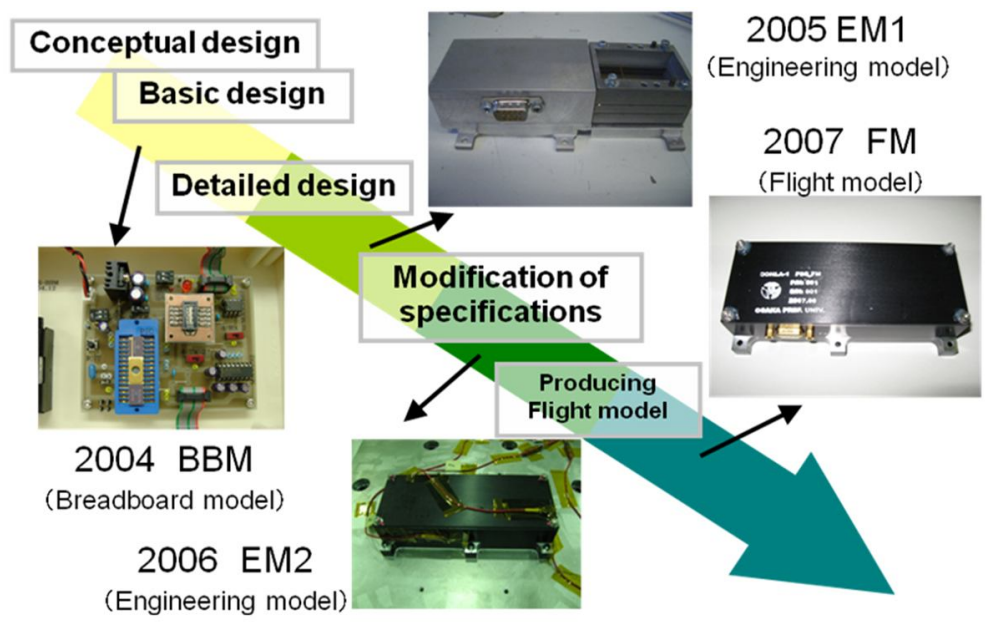

Fig. 2: Development of Fudai Sun Sensor (FSS). 


\subsection{Summary of FSS}

The FSS comprises of a surface component and a light-receiving component. The surface component usually has a slit or a pinhole to limit incident light. In the light-receiving component, the electric current output of solar battery cells or the light-receiving point is detected by a CCD to measure the angle of incidence. In contrast to regular sun sensors, the FSS employs a string to create shade. Table 2 lists the specifications of the FSS. The FSS is a uniaxial sun sensor: it measures the angle between the spin axis of the satellite and sunlight. This angle is defined as the total sun angle (TSA). As shown in Fig. 3, the intensity of sunlight is reduced by using an ND filter. A string placed between the ND filter and the linear sensor forms the shade over the linear sensor.Figure 4 shows a block diagram of the FSS. The linear sensor measures the position and brightness of the shade. These data are transformed into the digital format by an A/D converter having a built-in microcomputer, and the TSA is calculated. When the operation mode of the FSS changes, the ground station sends a command to the FSS through an amateur-band transponder and receiver (HTRX).

Table 2: Specifications of Fudai Sun Sensor (FSS).

\begin{tabular}{|l|l|}
\hline Mass & $0.450 \pm 0.050 \mathrm{~kg}$ \\
\hline Size & about $80 \times 150 \times 39 \mathrm{~mm}$ \\
\hline Installed satellite & SOHLA-1 \\
\hline Maximum consumption power & $\leq 1 \mathrm{~W}$ \\
\hline Feasible temperature & $-20^{\circ} \mathrm{C}-40^{\circ} \mathrm{C}$ \\
\hline Measurement method & one string method \\
\hline Detection accuracy & $2^{\circ} \sim 3^{\circ}$ (on board) \\
& $1^{\circ}$ (off board / aim) \\
\hline Detection range & $58 \pm 29^{\circ}$ (on board) \\
& $48 \pm 25^{\circ}$ (off board / aim) \\
\hline Life span & 3 months \\
\hline
\end{tabular}

Table 3: Modes of Operations of FSS.

\begin{tabular}{|l|l|}
\hline MODE & FUNCTION \\
\hline Standby mode & Turn on FSS \\
\hline Normal mode & Obtain TSA at $1 \mathrm{~Hz}$ \\
\hline High-speed mode & Obtain TSA at $5 \mathrm{~Hz}$ \\
\hline Message mode & $\begin{array}{l}\text { Output character on } \\
\text { program area }\end{array}$ \\
\hline
\end{tabular}


Conversely, telemetry from the FSS is sent to the ground station through HTRX. As shown in Table 3, the FSS prepares some operation modes for its own control. Moreover, the FSS has a changing threshold value function in order to vary the threshold value to the strength of sunlight so that the shade can be discerned manually or automatically (valid for normal or high-speed mode). The FSS also employs reset functions for hardware and software troubleshooting.
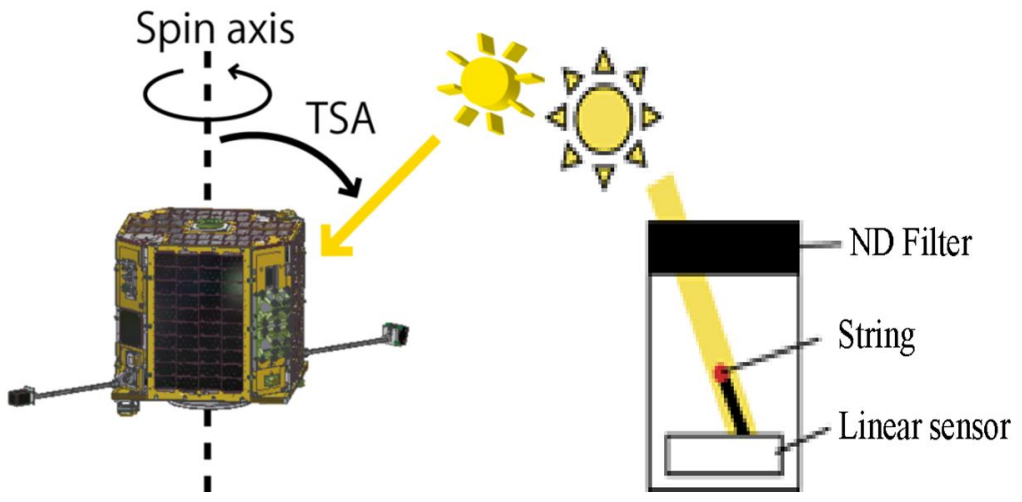

Fig. 3: Structure of FSS.

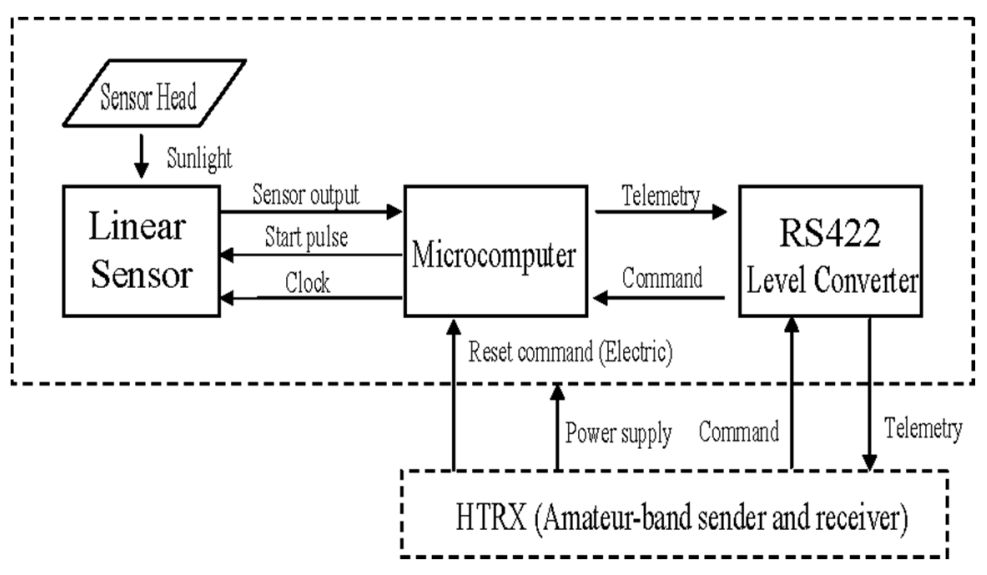

Fig. 3: Bock diagram of FSS.

\subsection{Specification Definitions}

The FSS is an experimental component that is used in the nominal position. Considering some errors and problems, the detection range can therefore be defined at $\pm 30^{\circ}$ from the measurement center, which is the normal TSA of MAIDO-1.

As shown in Fig. 5, the detection range $\theta$ is given as follows:

$$
\theta=180^{\circ}-\left(\tan ^{-1} \frac{\mathrm{L} / 2-d L}{h}+\tan ^{-1} \frac{\mathrm{L} / 2+d L}{h}\right)
$$


On the FSS, $L=9 \mathrm{~mm}$ and the measuring center $T S A=67.5^{\circ}$. Thus, the distance between the light-receiving element and the sensor head when the detection range is $60^{\circ} \mathrm{can}$ be calculated.

The relationship between the detection range and the maximum resolution is described as follows:

$$
\text { Maximum resolution }=\frac{\text { Detection } \text { range }}{\text { The number of pixel }}
$$

The FSS consists of a 64 pixel linear sensor and its detection range is 60 [deg]; thus, its maximum resolution is $0.9375^{\circ}$. Measurement errors and the size of pixels of the linear sensor, however, should be considered. The target accuracy is therefore defined as $1^{\circ}$.

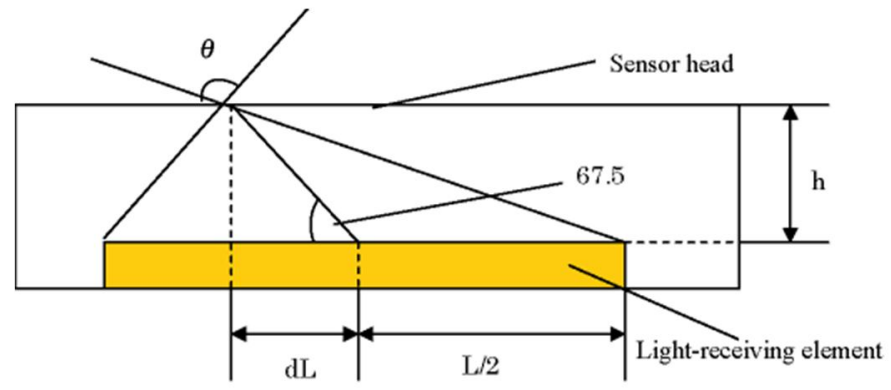

Fig. 4: Light-receiving element and sensor head.

\subsection{Detection Accuracy}

In order to reconfirm the validity of the ND filter design for EM2 and to confirm the measurement accuracy of the FSS, an accuracy test (quasi-sunlight irradiation test) was performed in the solar battery evaluation room of the JAXA Tsukuba Space Center. The accuracy was found to be about $0.5^{\circ} \sim 1^{\circ}$. Figure 6 compares the actual value of the sun angle and the sun angle value obtained from the FSS.

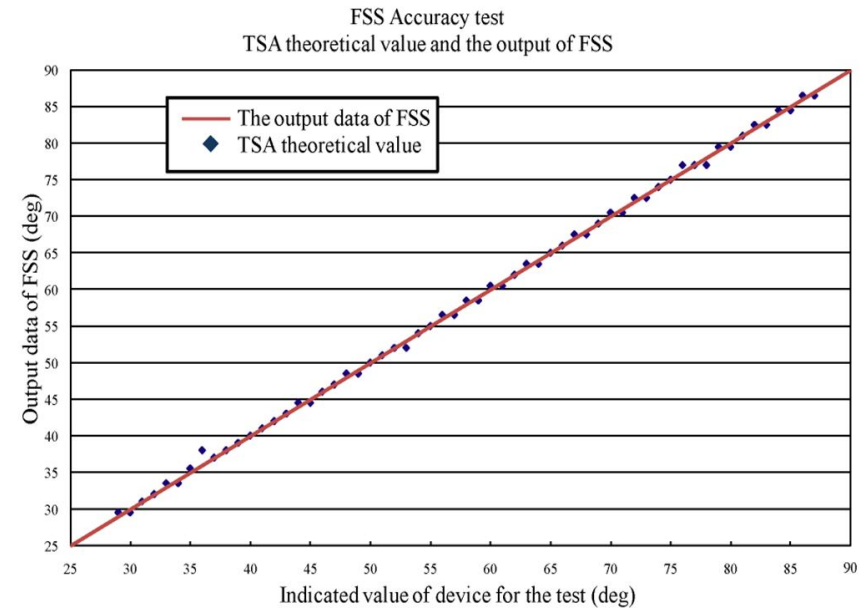

Fig. 6: TSA theoretical value and output of FSS. 
In order to develop a "space" component, resistance to space as well as the launching environment is extremely important. It mainly consists of temperature resistance, vacuum resistance, and vibration resistance.

\section{ON-ORBIT OPRATIONS AND EXPERIMENTS}

MAIDO-1 was launched on January 23, 2009, as a subsatellite of the Greenhouse Gases Observing Satellite (GOSAT) aboard H-IIA Launch Vehicle No. 15. The satellite was in the initial functional verification operation for about one month after completing its critical operation on January 27, 2009 (JST). Then, the normal operation phase was executed smoothly for three months (March-May 2009) and was immediately followed by the extended operation phase (June-October 2009).

\subsection{Operation/Control System}

Satellite operation/control and the acquisition of telemetry data, such as, experimental data and image data, were conducted by the JAXA Space Technology Demonstration Research Center at Tsukuba Space Center. The ground station network of JAXA, Masuda, Okinawa, and Katsu'ura stations supported the communications with the satellite using Sband frequencies. An amateur-band radio transceiver (HTRX) was also on-board, and Osaka Prefecture University also operated its own amateur-band ground station and performed an on-orbit demonstration of the newly developed solar sensor (Fudai Sun Sensor, FSS). The data measured by the FSS was sent to the ground as amateur-band telemetry. Satellites daily revolve around the earth for about 98 min to pass over Japan in the afternoon and late night hours; over 25 students were participating in the operation of the satellite operation by changing of the crew members. Moreover, SOHLA was working for the civil service in conjunction with amateur radio and amateur radio clubs, and its daily operations were published on the web. Figure 7 shows the system configuration of the operation and control consisting of S-band and amateur radio frequency band ground stations.

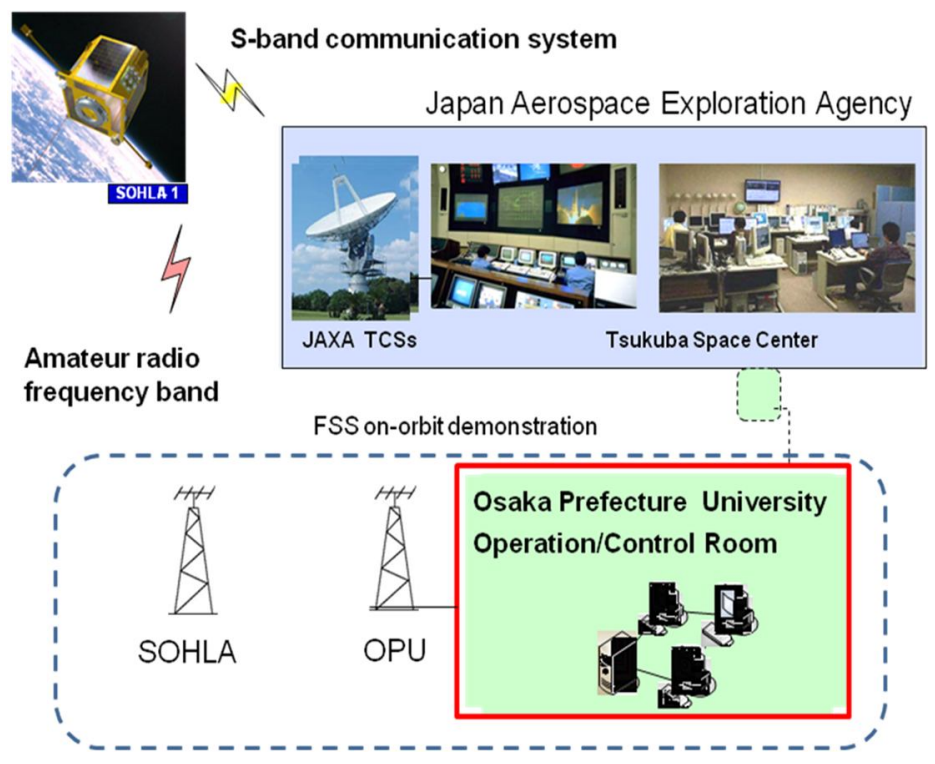

Fig. 7: Operation and communication stations. 


\subsection{On-Orbit Demonstration of FSS}

On-orbit test of the FSS was performed using an amateur-band communication system to obtain the experimental measurements as the telemetry data.Figure 8 is a graphical depiction of the telemetry obtained from the FSS showing the CCD sensor output vs. sensor element number. As compared to the results of ground quasi-sunlight irradiation test, it is observed that the shadow of the string has a clearer boundary. The TSA is geometrically obtained from the sensor numbers corresponding to the boundaries of the shadow. The time sequences of the averaged CCD output are shown in Figs. 9and 10 for the normal mode andhigh-speed mode, respectively. The cyclic variation of output level represents the spin of the satellite and the time between the peaks indicates the spin period.

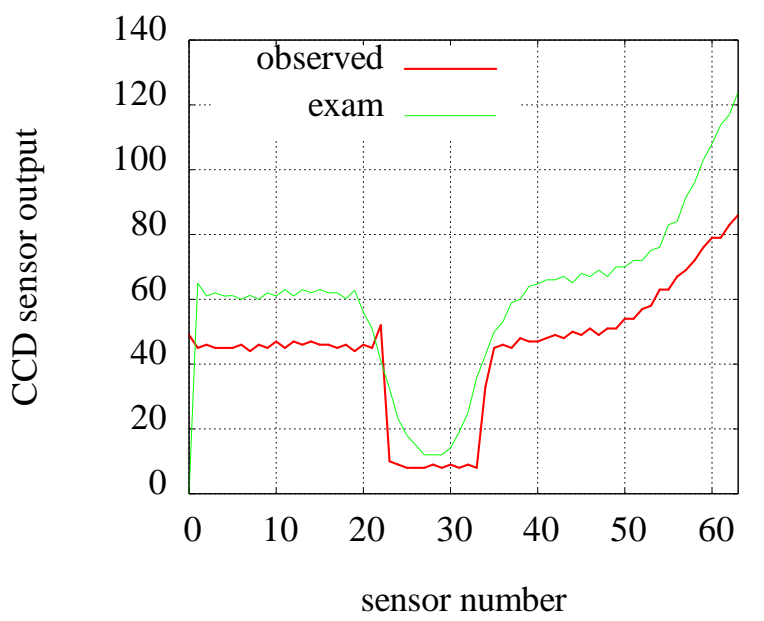

Fig. 8: CCD sensor output (on-orbit test/ground test).

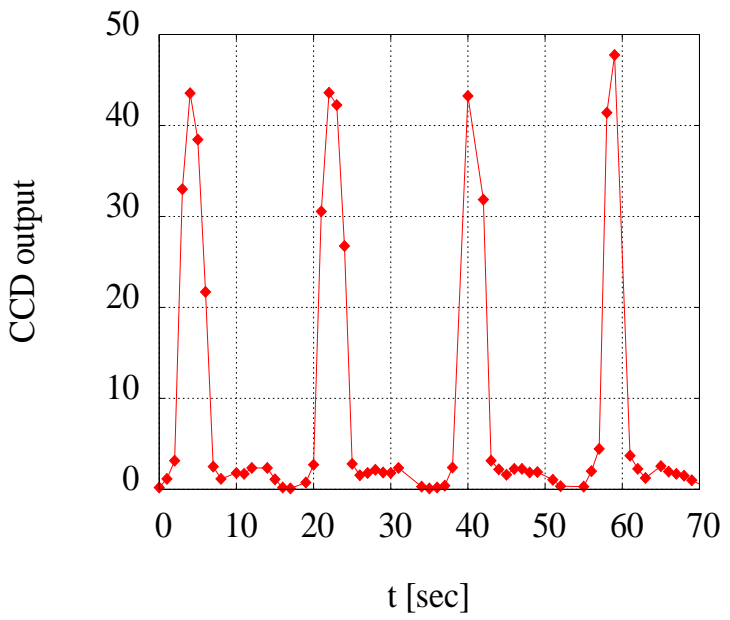

Fig. 9: Time sequence of CCD output (Normal Mode). 


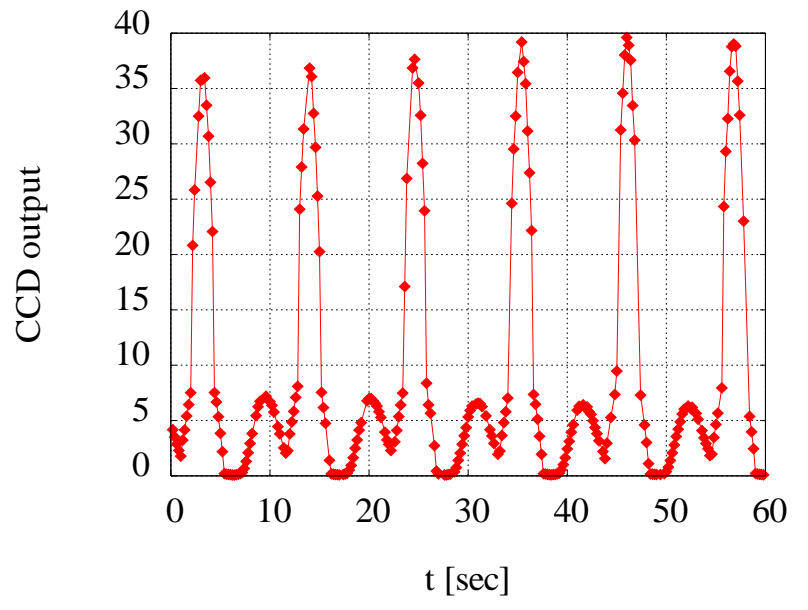

Fig. 10: Time sequence of CCD output (High-speed Mode).

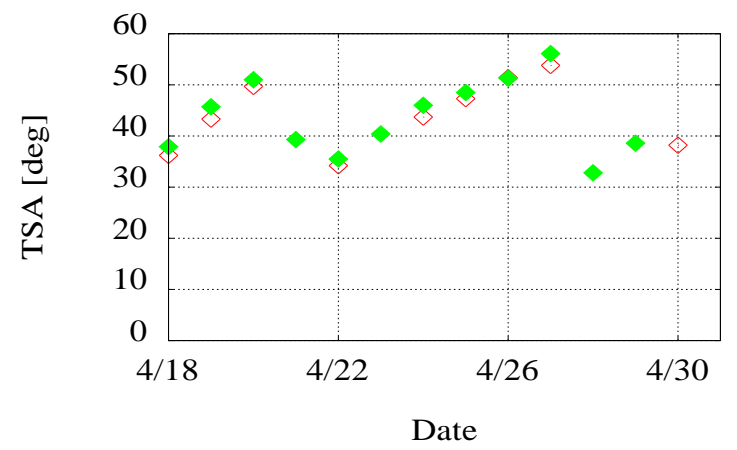

TSA (FSS)

TSA (FMS)

Fig. 11: Daily variation in TSA.

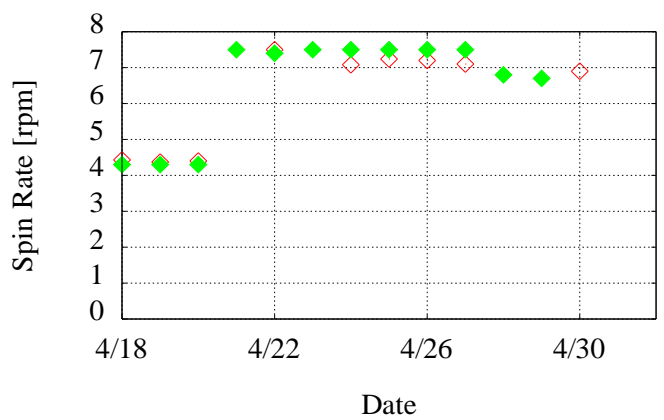

Spin Rate (FSS)
Spin Rate (FMS)

Fig. 12: Daily variation in spin rate.

Figures 11 and 12show the daily variations in of TSA and spin rate of the satellite, respectively. Average measurements of FSS are plotted for comparison with the SOHLA-1 bus-sensor (a flax magnetic sensor, FMS) estimates. Although deviations of $-1.0^{\circ} \sim-2.5^{\circ}$ are 
observed, the daily variations are congruous. These results demonstrate the usefulness of the sensor.

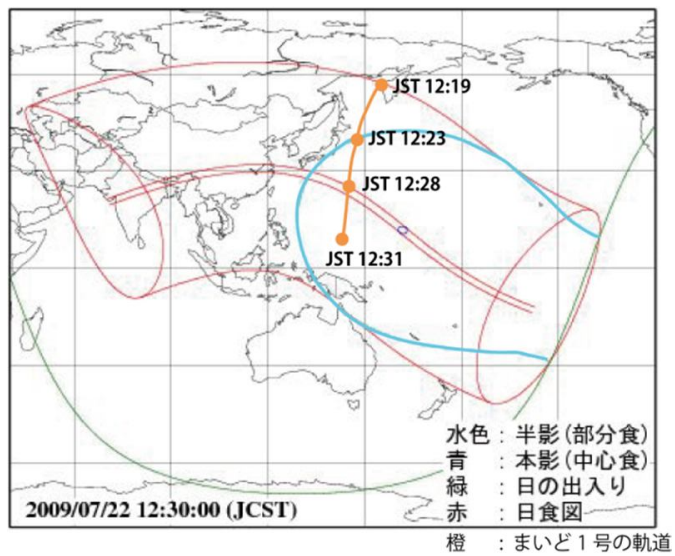

Fig. 13: Trajectories of MAIDO-1 and solar eclipse.

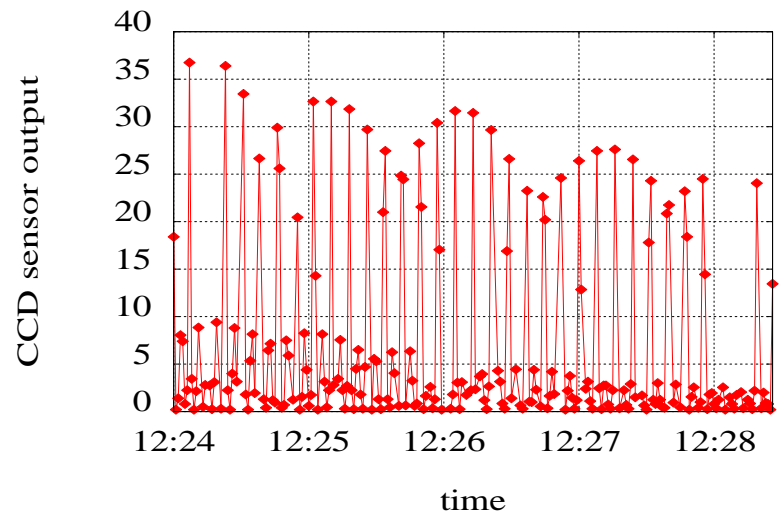

Fig. 14: Time sequence of sun sensor output (at solar eclipse).

A solar eclipse was observed in Asia and the Pacific on July 22, 2009. We successfully observed the solar eclipse using the FSS. Figure 13 shows that the on-earth trajectoriesof MAIDO-1(orange line) and the center of the region under the solar eclipse (double red line)crosses each other at JST 12:28. Figure 14 shows the average solar sensor CCD photodetector output (representing the intensity of the received sun light). Normally, the data is almost steady and the peak value is constant; however, the peak value for the solar eclipse decreases as SOHLA-1 approaches the centre of the eclipse. The maximum reduction was about $60 \%$ of the normal level at 12:28.

\section{CONCLUSION}

The development of the microsatellite MIAIDO-1 and FSS has been presented. The details of the operation and a brief summary of the on-orbit demonstration of the FSS have also been presented.The detection accuracy of FSS was estimated to be $0.5^{\circ} \sim 1^{\circ}$ by on-ground 
experiment and it was confirmed in on-orbit operation. This performance is enough for applying to a sun tracking attitude control system. The developed sensor is only a prototype model, and there are many challenges to finish it as a practically useful space instrument for microsatellites, e.g., the microminiaturizing of the hardware system through MEMS technology.

\section{ACKNOWLEDGEMENT}

We appreciate the technical support from Japan Aerospace Exploration Agency (JAXA) and Advanced Engineering Services (AES) Co. Ltd.

\section{REFERENCES}

[1] H.Okubo, H.Azuma, and M.Chiba, "Participation of Students for the Development of the Small Satellite SOHLA-1 and the Role of the Small Satellite Research Center," Proceedings of the 25th International Symposium on Space Technology and Sciences, pp. 1360-1365 (2006).

[2] H.Okubo, H.Azuma, and M. Chiba, "Development and Operation of Micro-Satellite SOHLA1(MAIDO-1)," International Astronautical Congress, IAC-09-B4.3.8, 6 pages, 2009.

[3] H. Okubo, T. Isono, K. Obata, "Development and Operation of Micro-Satellite MAIDO-1 and onorbit Demonstration of Sun Sensor," IFAC International Conference on Aerospace Control, Nara, 2010.

[4] T. Obata, K. Itoh, Y. Kakimi, and H. Okubo, "Development of Fudai Sun Sensor (FSS)," Trans. JSASS, Space Technology Japan, vol. 7, pp.Tf_25-Tf_30, 2009.

[5] J.H. Hales and M. Pedersen, "Two-Axis MOEMS Sun Sensor for Pico Satellites," 16th Annual AIAA/USU Conference on Small Satellites, SSC02-VI-6, 2002. 